\title{
The Association Between Serum Lactate Dehydrogenase Level and in-hospital Death Due to Pulmonary Embolism
}

\section{Samad Ghaffari}

Cardiovascular Research center, Tabriz University of Medical Sciences

\section{Tooba Mohammadi}

Student Research Committee, Urmia University of Medical Sciences

Reza Hajizadeh ( $\square$ hajizadh.reza@gmail.com )

Department of cardiology, Urmia University of Medical Sciences, Urmia, Iran

Hadiseh Kavandi

Student Research Committee, Urmia University of Medical Sciences

\section{Kamran Mohammadi}

Cardiovascular Research center, Tabriz University of Medical Sciences

\section{Mehdi Mohebalizadeh}

Student Research Committee, Urmia University of Medical Sciences

\section{Sahar Ghodratizadeh}

Department of Anesthesiology, Urmia University of Medical Sciences

\section{Research Article}

Keywords: pulmonary embolism, outcome, lactate dehydrogenase, hospital death

Posted Date: March 5th, 2021

DOl: https://doi.org/10.21203/rs.3.rs-276184/v1

License: (9) This work is licensed under a Creative Commons Attribution 4.0 International License. Read Full License 


\title{
The association between serum lactate dehydrogenase level and in-hospital death due to pulmonary embolism
}

Samad Ghaffari ${ }^{1}$, Tooba Mohammadi ${ }^{2}$, Reza Hajizadeh ${ }^{3 *}$, Hadiseh Kavandi ${ }^{2}$, Kamran Mohammadi $^{1}$, Mehdi Mohebalizadeh², Sahar Ghodratizadeh ${ }^{4}$

1- Cardiovascular Research Center, Tabriz University of Medical Sciences, Tabriz, Iran

2-Student Research Committee, Urmia University of Medical Sciences, Urmia, IRAN

3- Department of cardiology, Urmia University of Medical Sciences, Urmia, Iran

4- Department of Anesthesiology, Urmia University of Medical Sciences, Urmia, Iran

${ }^{*}$ Corresponding author: Reza Hajizadeh, Department of cardiology, Urmia University of Medical Sciences, Urmia, Iran

Iran. Tel: +984433440000, hajizadh.reza@gmail.com

\begin{abstract}
:
Background: There are few studies evaluating the prognostic value of lactate dehydrogenase $(\mathrm{LDH})$ in patients with pulmonary embolism (PE). We analyzed possible power of serum LDH level to predict in-hospital mortality.
\end{abstract}

Methods: In this cross-sectional study 217 patients with confirmed PE diagnosis with CT angiography and available serum LDH level at first 24-hours upon admission were included.

Results: The mean age of patients were $63.04 \pm 16.81$ years old, 23 patients $(10.6 \%)$ died during hospitalization. Multivariate analysis showed that only LDH, WBC were independent predictors of in-hospital mortality, however this association was not significant.

Conclusions: In patients with pulmonary embolism, LDH can be a good prognostic marker for predicting in-hospital death.

Keyword: pulmonary embolism, outcome, lactate dehydrogenase, hospital death

\section{Background:}

Pulmonary embolism (PE), together with deep vein thrombosis (DVT) termed as venous thromboembolism (VTE), can be a life-threatening condition. So, accurate and immediate diagnosis is critical. (1) 
Since signs and symptoms of PE are non-specific with a wide variety, $(1,2)$ the role of imaging modalities and laboratory values are very important to help confirm the diagnosis. Computed tomography pulmonary angiography (CTPA) and ventilation-perfusion (V/Q) lung scanning are the two most widely used diagnostic tools in this way. However, both of them are timeconsuming, costly and can cause harm to the patients such as those related to contrast agent and radiation. (3) Another challenging matter is overdiagnosis of smaller subsegmental emboli by very sensitive scanners. (1)

Validated Wells (4) and revised Geneva rules (5), which categorize patients according to the pre-test probability of PE are frequently used as clinical tools to help diagnosis of PE. In a nonhigh risk patient based on one of these criteria, D-dimer level below $500 \mu \mathrm{g} / \mathrm{L}$ can rule out the PE diagnosis with high confidence in about $20 \%$ to $30 \%$ of patients without the need for additional imaging. (6)

Efforts are being made to reduce the amount of unnecessary imaging (CTPA and V/Q). On the other hand, these imaging techniques are not available everywhere. Thus, it will be helpful to find an available serum marker which would be related to occurrence of PE and its prognosis.

LDH is an enzyme found in almost all cells in the body. It has five different subtypes with different distribution in tissues and releases in the bloodstream with cell and/or tissue injuries. (7)

According to previous studies, significant association was found between serum LDH level and pump thrombosis in patients who have left ventricular assist device (LVAD). (8, 9) LDH-1 isoenzyme especially showed high relation to pump thrombosis.(10) Significant correlation between elevated LDH level and some other thrombotic events has been demonstrated. In a study about predictive factors of splanchnic vein thrombosis, $\mathrm{LDH}<500 \mathrm{U} / \mathrm{L}$ was found to be associated with thrombosis (13).(11) In another study, an association was seen between elevated LDH level -as a marker of hemolysis- and thrombosis risk in paroxysmal nocturnal hemoglobinuria patients. $(12,13)$

Elevated serum LDH was identified as an independent risk factor for venous thromboembolism in patients with testicular germ cell tumor undergoing chemotherapy. (13)

Higher serum LDH level was found in PE patients.(14) In another study, significantly elevated pleural fluid LDH1 and LDH 3 isoenzymes was found in PE.(15)

Importance of LDH as a marker of severity in PE has been stated in some studies $(16,17)$ while others has been reported no significant association between PE and LDH level. (15) Based on another study, no association was found between LDH level and bleeding or thrombosis, but higher LDH level on ICU admission was shown to be significantly associated with increased 7day and 30-day mortality. (18)

In current study, we want to find out the possible utility of serum LDH level to classify these patients to high and low risk groups. 


\section{Methods:}

In this cross-sectional study 217 patients with acute PE were included. Our inclusion criteria included as hospitalized patients aged over 18 years, confirmed PE diagnosis with CT angiography and available serum LDH level at first 24-hours upon admission.

Patients with hepatic and renal diseases, pregnant women, those with hemolytic disorders, left ventricular infarction, recent stroke, positive history of pancreatic cancer, acute and chronic infections and reticuloendothelial- related diseases were excluded.

Diagnosis of PE was made by CTPA (Siemens 32-slice computed tomography scanners). Two expert radiologists were investigated CTPA images as blinded fashion.

This study was approved by ethics committee of our University. All patients had signed informed consent form and patient anonymity was preserved in our study.

Any death in a hospitalized patient due to PE was defined as in-hospital mortality. Other causes of death during hospitalization were excluded. SBP $<90 \mathrm{mmHg}$ or $\mathrm{O}_{2}$ saturation $<90 \%$ in combination with right ventricular dysfunction were considered as indication for fibrinolytic therapy.

We measured simplified Pulmonary Embolism Severity Index (SPESI) value for all the patients. Factors including age over 80 years, positive history of cancer, heart rate below 110 beats/minute, chronic cardiopulmonary disease, systolic blood pressure less than $100 \mathrm{~mm} \mathrm{Hg}$, and oxyhemoglobin saturation less than $90 \%$ were assessed in this scoring system and each variable has one point. The patient will categorized as high risk even with presence of one point. (19)

Information about demographic characteristics of the patients such as age, sex, past medical history as well as presenting vital sings and oxygen saturation were collected from their medical records. Echocardiography and CTPA findings, laboratory values especially LDH level within the first 24-hour of admission, fibrinolytic therapy, need for mechanical ventilation and/or surgical thrombectomy, reports on in-hospital death and hospitalization duration were recorded through designed questionnaire. The association between these factors and serum LDH level was assessed.

IBM SPSS V.22 software was used for statistical analysis (IBM Corp., Armonk, NY, USA). We used t-test for quantitative values and chi-squire test for qualitative variables. Multiple linear regression and ROC (receiver operating characteristics) curve were used to find cutoff value for LDH level and mortality. 


\section{Results:}

In this cross sectional study we included 217 patients with definite diagnosis of pulmonary embolism. The mean age of patients was $63.04 \pm 16.81,98$ patients $(45.2 \%)$ were female. During hospital admission 23 patients (10.6\%) died. Past medical history showed that 40 patients (18.4\%) had diabetes mellitus, 78 patients (35.9\%) had hypertension, 31 patients (14.3\%) had history of smoking. Pulmonary embolism was confirmed in all cases by computed tomography (CT) angiography. Table 1 shows demographic, laboratory and physical exam findings in patients with pulmonary embolism according to their in-hospital mortality. Table 2 shows association between LDH and other variables.

Univariate analysis showed that among laboratory data findings, higher levels of LDH, white blood cells (WBC), red distribution width (RDW) had significant association with in-hospital mortality. (P values<0.05). (Table 2 ) only LDH, WBC were independent predictors of in-hospital mortality, however this association was not significant statistically. (Table 2) ROC curve (receiver operating characteristic curve) showed that a LDH cut-off value of $515 \mathrm{U} / \mathrm{l}$ had a sensitivity of $91.3 \%$ and specificity of $45.9 \%$ in predicting in-hospital mortality (95\% confidence interval $=0.636-0.761, p=0.0003$ ). (Figure1) 
Table 1; the association between demographic, laboratory and physical exam findings and hospital death.

\begin{tabular}{|c|c|c|c|}
\hline & \multicolumn{2}{|c|}{ Hospital death } & \multirow[b]{2}{*}{$\mathrm{p}$-value } \\
\hline & $\begin{array}{c}\text { Yes } \\
23(10.6) \\
\end{array}$ & $\begin{array}{c}\text { NO } \\
194(89.4) \\
\end{array}$ & \\
\hline Age & $64.04 \pm 18.18$ & $62.93 \pm 16.69$ & 0.763 \\
\hline Gender(female) & $13(56.5 \%)$ & $85(43.8 \%)$ & 0.247 \\
\hline Lactate dehydrogenase (LDH) & $873.65 \pm 514.15$ & $609.15 \pm 343.57$ & 0.024 \\
\hline Tricuspid regurgitation gradient & $39.65 \pm 16.13$ & $34.73 \pm 20.32$ & 0.264 \\
\hline White blood cells $\left(\times 10^{3}\right)$ & $13.69 \pm 44.46$ & $10.51 \pm 15.07$ & 0.003 \\
\hline Hemoglobin & $23.74 \pm 2.77$ & $12.96 \pm 2.15$ & 0.647 \\
\hline Mean corpuscular volume & $80.48 \pm 5.43$ & $81.29 \pm 5.43$ & 0.496 \\
\hline Platelets $\left(\times 10^{3}\right)$ & $213.22 \pm 86.50$ & $206.07 \pm 72.91$ & 0.664 \\
\hline Red cell distribution width (RDW) & $16.40 \pm 2.32$ & $15.07 \pm 2.58$ & 0.019 \\
\hline Total cholesterol & $160.13 \pm 37.19$ & $167.16 \pm 42.45$ & 0.449 \\
\hline Triglyceride & $141.74 \pm 67.86$ & $142.43 \pm 97.78$ & 0.974 \\
\hline Heart rate & $104.83 \pm 17.01$ & $96.35 \pm 19.54$ & 0.048 \\
\hline Systolic blood pressure & $101.22 \pm 18.77$ & $121.53 \pm 21.14$ & $<0.001$ \\
\hline Diastolic blood pressure & $63.91 \pm 12.77$ & $74.72 \pm 12.06$ & $<0.001$ \\
\hline $\mathrm{O} 2$ saturation & $81.30 \pm 7.92$ & $87.62 \pm 9.15$ & 0.001 \\
\hline Diabetes mellitus & $6(26.1 \%)$ & $34(17.5 \%)$ & 0.391 \\
\hline Hypertension & $9(39.1 \%)$ & $69(35.6 \%)$ & 0.895 \\
\hline $\mathrm{T}$ inversion in $\mathrm{V} 1-\mathrm{V} 3$ & $8(34.8 \%)$ & $71(36.6 \%)$ & 0.846 \\
\hline Right ventricular enlargement & $19(82.6 \%)$ & $122(62.9 \%)$ & 0.067 \\
\hline Right ventricular dysfunction & $19(82.6 \%)$ & $114(58.8 \%)$ & 0.040 \\
\hline Massive Emboli & $2(8.7 \%)$ & $4(2.1 \%)$ & $<0.001$ \\
\hline Simplified PESI score $\geq 1$ & $23(100.0 \%)$ & $124(63.9 \%)$ & $<0.0001$ \\
\hline
\end{tabular}




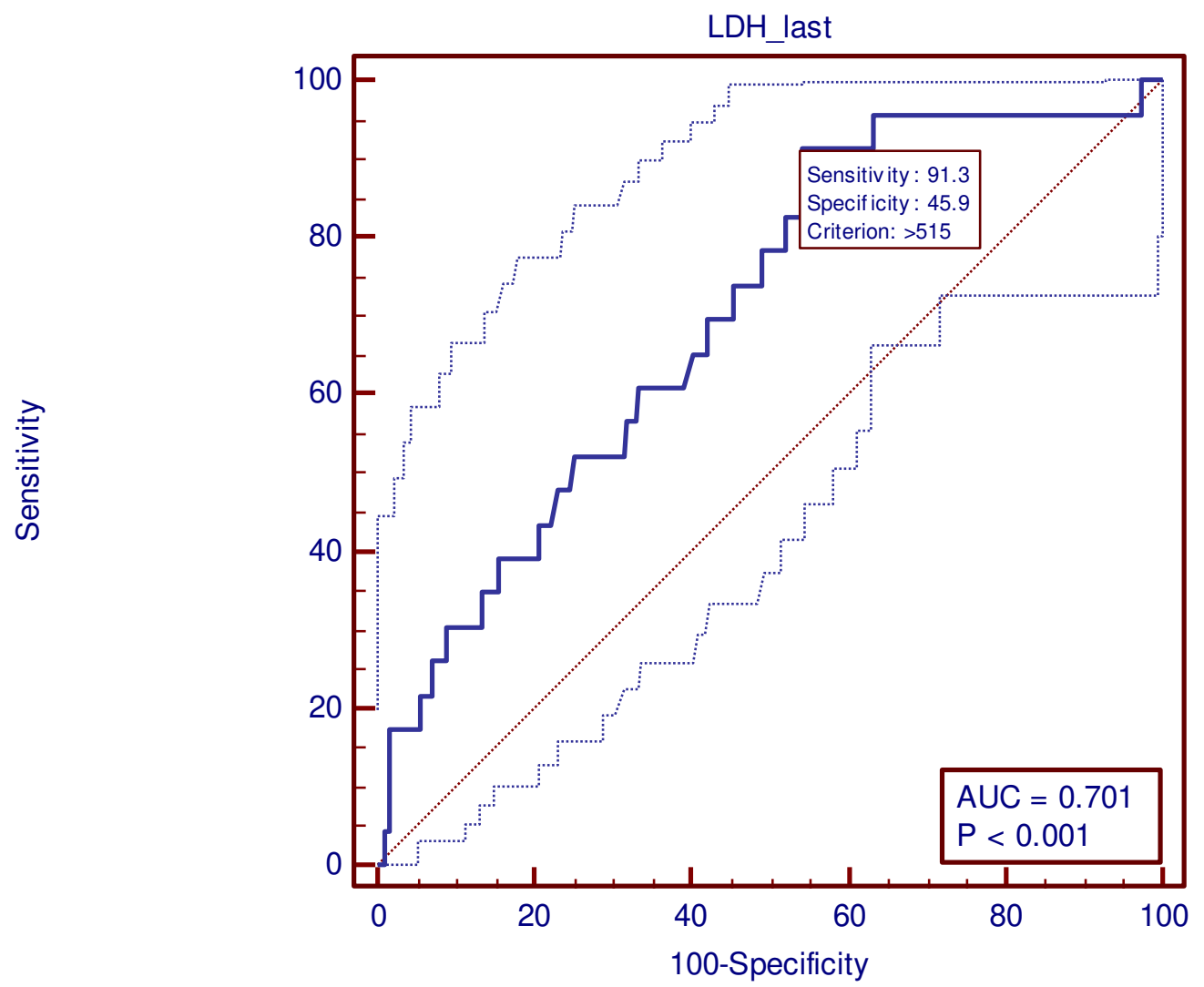

Area under the ROC curve (AUC)

\begin{tabular}{l|c}
\hline Area under the ROC curve (AUC) & 0.701 \\
Standard Error ${ }^{\mathrm{a}}$ & 0.0556 \\
\hline $95 \%$ Confidence interval ${ }^{\mathrm{b}}$ & 0.636 to 0.761 \\
\hline z statistic & 3.625 \\
\hline Significance level P (Area=0.5) & 0.0003 \\
\hline a
\end{tabular}

${ }^{\text {a }}$ DeLong et al., 1988

${ }^{b}$ Binomial exact

Figure 1; An ROC curve (receiver operating characteristic curve) shows the best cut off point for LDH to predict hospital death. 
Table 2; univariate and multivariate analysis of risk factors of in-hospital mortality

\begin{tabular}{|c|c|c|c|c|c|c|}
\hline \multirow{2}{*}{ Variable } & \multicolumn{3}{|c|}{ Univariate } & \multicolumn{3}{|c|}{ multivariate } \\
\hline & Unadjusted OR & $95 \% \mathrm{CI}$ & $\mathrm{P}$-value & Unadjusted OR & $95 \% \mathrm{CI}$ & P-value \\
\hline RV strain & 1.082 & $0.437-2.679$ & 0.864 & & & \\
\hline O2 saturation & 0.932 & $0.893-0.974$ & 0.002 & 0.996 & $0.930-1.067$ & 0.907 \\
\hline WBC & 1.00 & $1.00-1.00$ & $<0.001$ & 1.000 & $1.000-1.000$ & 0.052 \\
\hline $\mathrm{Cr}$ & 2.077 & $1.047-4.119$ & 0.036 & 1.091 & $0.389-3.064$ & 0.868 \\
\hline Heart rate & 1.022 & $1.000-1.045$ & 0.051 & & & \\
\hline $\begin{array}{l}\text { Systolic blood } \\
\text { pressure }\end{array}$ & 0.949 & 0.924-0.974 & $<0.001$ & 0.968 & 0.929-1.009 & 0.126 \\
\hline $\begin{array}{l}\text { Diastolic blood } \\
\text { pressure }\end{array}$ & 0.934 & $0.900-0.968$ & $<0.001$ & 0.991 & $0.930-1.057$ & 0.794 \\
\hline RVdysfunct & 0.300 & $0.915-0.098$ & 0.034 & 2.327 & $0.668-8.103$ & 0.185 \\
\hline RDW & 1.189 & $1.378-1.026$ & 0.022 & 1.141 & $0.925-1.408$ & 0.217 \\
\hline $\mathrm{LDH}$ & 1.001 & $1.002-1.000$ & 0.005 & 1.001 & $1.000-1.003$ & 0.082 \\
\hline massiveEmboli & 0.168 & $0.511-0.055$ & 0.002 & 0.165 & $0.651-0.042$ & 0.010 \\
\hline simpPESIsum & 3.047 & $4.857-1.912$ & $<0.001$ & 2.304 & $4.266-1.245$ & 0.008 \\
\hline
\end{tabular}

WBC; white blood cell, Cr; creatinine, PESI; pulmonary embolism severity index RV; right ventricle, WBC; white blood cell, RDW; red cell distribution width, PESI; pulmonary embolism severity index

\section{Discussion:}

In this cross-sectional study, we evaluated the level of lactate dehydrogenase in 217 patients with a definite diagnosis of pulmonary embolism. Our study showed that serum LDH was associated with higher risk of in-hospital death, but this association was not significant in multivariate analysis. Nowadays, with the pandemic of COVID 19, the importance of LDH as a prognostic factor in these patients has been raised. The incidence of pulmonary embolism is estimated to be up to $30 \%$ in COVID 19 patients who are admitted in intensive care units despite proper deep vein thrombosis prophylaxis. $(20,21)$ In patients infected with novel COVID-19, elevated LDH serum level has been associated with more severe disease and worse prognosis. (22) Increased LDH has been linked to higher risk of ARDS (23), in ICU complications (24), and death. $(22,23)$ 
In line with our study, Serum LDH level has been reported to be higher in massive PTE compared to sub-massive and non-massive PTE. $(25,26)$ The increased LDH level was associated with higher pulmonary artery pressure, right ventricular dysfunction. (25)

Pulmonary thromboembolism is one of the most dangerous complications involving cardiovascular system. (27) The importance of evaluating and predicting the course and outcome of the disease has been an era of interest for researchers. Lactate dehydrogenase is abundantly made in the human body.It has 5 types of isozymes, LDH-1 and LDH-3 isozymes are presented in cardiomyocytes and pneumocyts respectively. $(20,28)$ Karlsson et al showed that LDH had significant correlation with hypoxic ischaemic encephalopathy in newborn infants. (29) By catalyzing pyruvate to lactate, LDH is an important enzyme in anaerobic metabolism of glucose during hypoxia. (30)

A recent study showed that patients with COVID-19 and high LDH levels are more susceptible to develop acute respiratory distress syndrome. (31) Increasing in cardiac, lung and hypoxic tissue damage makes LDH a suitable biomarker for predicting outcome of patients with pulmonary embolism. Ben et al suggested that using LDH-3 and D-dimer together could improve the diagnosis of PE. (32) Our study showed that LDH levels had association with cTnI. One study showed that in myocardial infarction, LDH and cTnl both were directly related to the extent of heart ischemia. (33) Our study showed that presence of massive embolism and higher sPESI were better predictors of in-hospital death, but higher LDH and WBC also could help in better differentiation of patients. There are a few studies investigating the association between LDH level in PE patients and in-hospital mortality. Leite et al studied 165 patients with acute PE and showed that LDH had significant association with in-hospital and late all-cause mortality. They showed that a LDH cut-off value of $310 \mathrm{U} / \mathrm{I}$ with a sensitivity of $54.5 \%$ and specificity of $71.3 \%$ could predict adverse outcome. (34) Our study by a larger sample size, showed that a LDH cutoff value of $515 \mathrm{U} / \mathrm{l}$ had a sensitivity of $91.3 \%$ and specificity of $45.9 \%$ in predicting in-hospital mortality. Further studies by revealing pathophysiology of underlying causes of LDH related morbidity and mortality could improve patients' management and outcome.

\section{List of abbreviations:}


LDH: lactate dehydrogenase

PE: pulmonary embolism

VTE: venous thromboembolism

CTPA: Computed tomography pulmonary angiography

LVAD: left ventricular assist device

ICU: Intensive care unite

\section{Ethics approval and consent to participate}

This study was approved by ethics committee of Urmai University of Medical Sciences and were performed in accordance with the principles of the Declaration of Helsinki, and the International Conference on Harmo-nisation notes for guidance on Good Clinical Practice (ICH/CPMP/135/95). All patients provided written informed consent prior to any study-related procedure

\section{Consent for publication}

Not applicable.

Availability of data and materials

Data of this study will be available by requesting through Email address of corresponding author.

Competing interests

The authors declare that they have no conflict of interest.

Funding

The authors declare no funding for this study

\section{Authors' contributions}

The study was designed by $\mathrm{SG}$ and $\mathrm{RH}$, data collected and manuscript written by TM, KM, MM, SG and HK interpreted the data, and $\mathrm{RH}$ revised the manuscript for important intellectual content. All authors read and approved the final manuscript

Acknowledgements

Pulmonary embolism registry of Tabriz University of Medical Sciences (Cardiovascular Research Center) supports data availability for this study.

\section{References:}

1. Stals MA, Klok FA, Huisman MV. Diagnostic management of acute pulmonary embolism in special populations. Expert Review of Respiratory Medicine. 2020:1-8.

2. Di Nisio M, van Es N, Büller HR. Deep vein thrombosis and pulmonary embolism. Lancet (London, England). 2016 Dec 17;388(10063):3060-73. PubMed PMID: 27375038. Epub 2016/07/05. eng.

3. Van Es N, Van der Hulle T, Büller H, Klok F, Huisman M, Galipienzo J, et al. Is stand-alone D-dimer testing safe to rule out acute pulmonary embolism? Journal of Thrombosis and Haemostasis. 2017;15(2):323-8.

4. Wells PS, Anderson DR, Rodger M, Ginsberg JS, Kearon C, Gent M, et al. Derivation of a simple clinical model to categorize patients probability of pulmonary embolism: increasing the models utility with the SimpliRED D-dimer. Thrombosis and haemostasis. 2000;83(03):416-20.

5. Le Gal G, Righini M, Roy P-M, Sanchez O, Aujesky D, Bounameaux H, et al. Prediction of pulmonary embolism in the emergency department: the revised Geneva score. Ann Intern Med. 2006;144(3):165-71. 
6. Lucassen W, Geersing G-J, Erkens PM, Reitsma JB, Moons KG, Büller H, et al. Clinical decision rules for excluding pulmonary embolism: a meta-analysis. Ann Intern Med. 2011;155(7):448-60.

7. Holmes RS, Goldberg E. Computational analyses of mammalian lactate dehydrogenases: human, mouse, opossum and platypus LDHs. Computational biology and chemistry. 2009;33(5):379-85.

8. Grabska J, Schlöglhofer T, Gross C, Maw M, Dimitrov K, Wiedemann D, et al. Early detection of pump thrombosis in patients with left ventricular assist device. ASAIO Journal: Artificial Organ Research and Development. 2020;66(4):348-54.

9. Thenappan T, Stulak JM, Agarwal R, Maltais S, Shah P, Eckman P, et al. Early intervention for lactate dehydrogenase elevation improves clinical outcomes in patients with the HeartMate II left ventricular assist device: Insights from the PREVENT study. The Journal of Heart and Lung Transplantation. 2018;37(1):25-32.

10. Topkara V, Garan A, Yuzefpolskaya M, Takeda K, Takayama H, Cagliostro B, et al. Lactate dehydrogenase isoenzyme monitoring in patients with continuous-flow left ventricular assist devices (CF-LVADs). The Journal of Heart and Lung Transplantation. 2016;35(4):S393.

11. Toqué L, Hamy A, Hamel JF, Cesbron E, Hulo P, Robert S, et al. Predictive factors of splanchnic vein thrombosis in acute pancreatitis: A 6-year single-center experience. Journal of Digestive Diseases. 2015;16(12):734-40.

12. Lee JW, Jang JH, Kim JS, Yoon S-S, Lee J-H, Kim Y-K, et al. Clinical signs and symptoms associated with increased risk for thrombosis in patients with paroxysmal nocturnal hemoglobinuria from a Korean Registry. International journal of hematology. 2013;97(6):749-57.

13. Paffenholz P, Grein K, Heidegger I, Nestler T, Grabbert M, Salem J, et al. Predictors of thrombosis in testicular cancer during platinum-based chemotherapy. World Journal of Urology. 2019;37(9):1907-

16.

14. Atikcan Ş, Atalay F, Turgut D, Ünsal E. Pulmonary thromboembolism: A retrospective evaluation of 42 cases. Solunum Hastaliklari. 2002;13:87-93.

15. Gülşen Z, Koşar PN, Gökharman FD. Comparison of multidetector computed tomography findings with clinical and laboratory data in pulmonary thromboembolism. Polish journal of radiology. 2015;80:252.

16. Babaoglu E, Hasanoglu HC, Senturk A, Karalezli A, Kilic H, Aykun G, et al. Importance of biomarkers in risk stratification of pulmonary thromboembolism patients. Journal of Investigative Medicine. 2014;62(2):328-31.

17. Babaoglu E, Hasanoglu HC, Senturk A, Karalezli A, Kilic H, Aykun G, et al. Importance of biomarkers in risk stratification of pulmonary thromboembolism patients. Journal of investigative medicine : the official publication of the American Federation for Clinical Research. 2014 Feb;62(2):32831. PubMed PMID: 24402296. Epub 2014/01/10. eng.

18. Russell L, Madsen M, Dahl M, Kampmann P, Perner A. Prediction of bleeding and thrombosis by standard biochemical coagulation variables in haematological intensive care patients. Acta Anaesthesiologica Scandinavica. 2018;62(2):196-206.

19. Ostovan MA, Ghaffari S, Pourafkari L, Dehghani P, Hajizadeh R, Nadiri M, et al. Modification of simplified pulmonary embolism severity index and its prognostic value in patients with acute pulmonary embolism. Heart, Lung and Circulation. 2016;25(2):184-90.

20. Henry BM, Aggarwal G, Wong J, Benoit S, Vikse J, Plebani M, et al. Lactate dehydrogenase levels predict coronavirus disease 2019 (COVID-19) severity and mortality: A pooled analysis. Am J Emerg Med. 2020;38(9):1722-6. PubMed PMID: 32738466. Epub 05/27. eng.

21. Sakr Y, Giovini M, Leone M, Pizzilli G, Kortgen A, Bauer M, et al. Pulmonary embolism in patients with coronavirus disease-2019 (COVID-19) pneumonia: a narrative review. Annals of intensive care.

2020;10(1):1-13. 
22. Zhou F, Yu T, Du R, Fan G, Liu Y, Liu Z, et al. Clinical course and risk factors for mortality of adult inpatients with COVID-19 in Wuhan, China: a retrospective cohort study. The lancet. 2020.

23. Wu C, Chen X, Cai Y, Zhou X, Xu S, Huang H, et al. Risk factors associated with acute respiratory distress syndrome and death in patients with coronavirus disease 2019 pneumonia in Wuhan, China. JAMA internal medicine. 2020.

24. Fan BE, Chong VCL, Chan SSW, Lim GH, Lim KGE, Tan GB, et al. Hematologic parameters in patients with COVID-19 infection. American journal of hematology. 2020;95(6):E131-E4.

25. Zhang Y, Yang Y-H, Pang B-S, Wang $\mathrm{C}$. The changes of serum enzymes and cardiac troponin I in patients with acute pulmonary thromboembolism. Zhonghua jie he he hu xi za zhi= Zhonghua jiehe he huxi zazhi= Chinese journal of tuberculosis and respiratory diseases. 2007;30(9):667-72.

26. Ben S-q, Ni S-s, Shen H-h, Shi Y-x, Huang S-b, Xu J-h, et al. The dynamic changes of LDH isoenzyme 3 and $D$-dimer following pulmonary thromboembolism in canine. Thrombosis research. 2007;120(4):575-83.

27. Sakr Y, Giovini M, Leone M, Pizzilli G, Kortgen A, Bauer M, et al. The clinical spectrum of pulmonary thromboembolism in patients with coronavirus disease-2019 (COVID-19) pneumonia: A European case series. Journal of critical care. 2020;61:39-44.

28. Martinez-Outschoorn UE, Prisco M, Ertel A, Tsirigos A, Lin Z, Pavlides S, et al. Ketones and lactate increase cancer cell "stemness," driving recurrence, metastasis and poor clinical outcome in breast cancer: achieving personalized medicine via Metabolo-Genomics. Cell cycle (Georgetown, Tex). $2011 \mathrm{Apr}$ 15;10(8):1271-86. PubMed PMID: 21512313. Pubmed Central PMCID: PMC3117136. Epub 2011/04/23. eng.

29. Karlsson M, Wiberg-Itzel E, Chakkarapani E, Blennow M, Winbladh B, Thoresen M. Lactate dehydrogenase predicts hypoxic ischaemic encephalopathy in newborn infants: a preliminary study. Acta paediatrica (Oslo, Norway : 1992). 2010 Aug;99(8):1139-44. PubMed PMID: 20236255. Epub 2010/03/20. eng.

30. Adeva-Andany M, López-Ojén M, Funcasta-Calderón $\mathrm{R}$, Ameneiros-Rodríguez $\mathrm{E}$, DonapetryGarcía C, Vila-Altesor M, et al. Comprehensive review on lactate metabolism in human health. Mitochondrion. 2014 Jul;17:76-100. PubMed PMID: 24929216. Epub 2014/06/15. eng.

31. Zhou Y, Ding N, Yang G, Peng W, Tang F, Guo C, et al. Serum lactate dehydrogenase level may predict acute respiratory distress syndrome of patients with fever infected by SARS-CoV-2. Ann Transl Med. 2020;8(17):1118-. PubMed PMID: 33145337. eng.

32. Ben SQ, Ni SS, Shen HH, Shi YX, Huang SB, Xu JH, et al. The dynamic changes of LDH isoenzyme 3 and D-dimer following pulmonary thromboembolism in canine. Thrombosis research. 2007;120(4):57583. PubMed PMID: 17258798. Epub 2007/01/30. eng.

33. Jaffe AS, Landt Y, Parvin CA, Abendschein DR, Geltman EM, Ladenson JH. Comparative sensitivity of cardiac troponin I and lactate dehydrogenase isoenzymes for diagnosing acute myocardial infarction. Clinical chemistry. 1996 Nov;42(11):1770-6. PubMed PMID: 8906075. Epub 1996/11/01. eng.

34. Leite L, Moura J, Ferreira R, Lazaro S, Madaleno J, Moreira N, et al. LDH as a predictor of inhospital and late mortality in acute pulmonary embolism. European heart journal. 2013;34(suppl_1). 
Figures

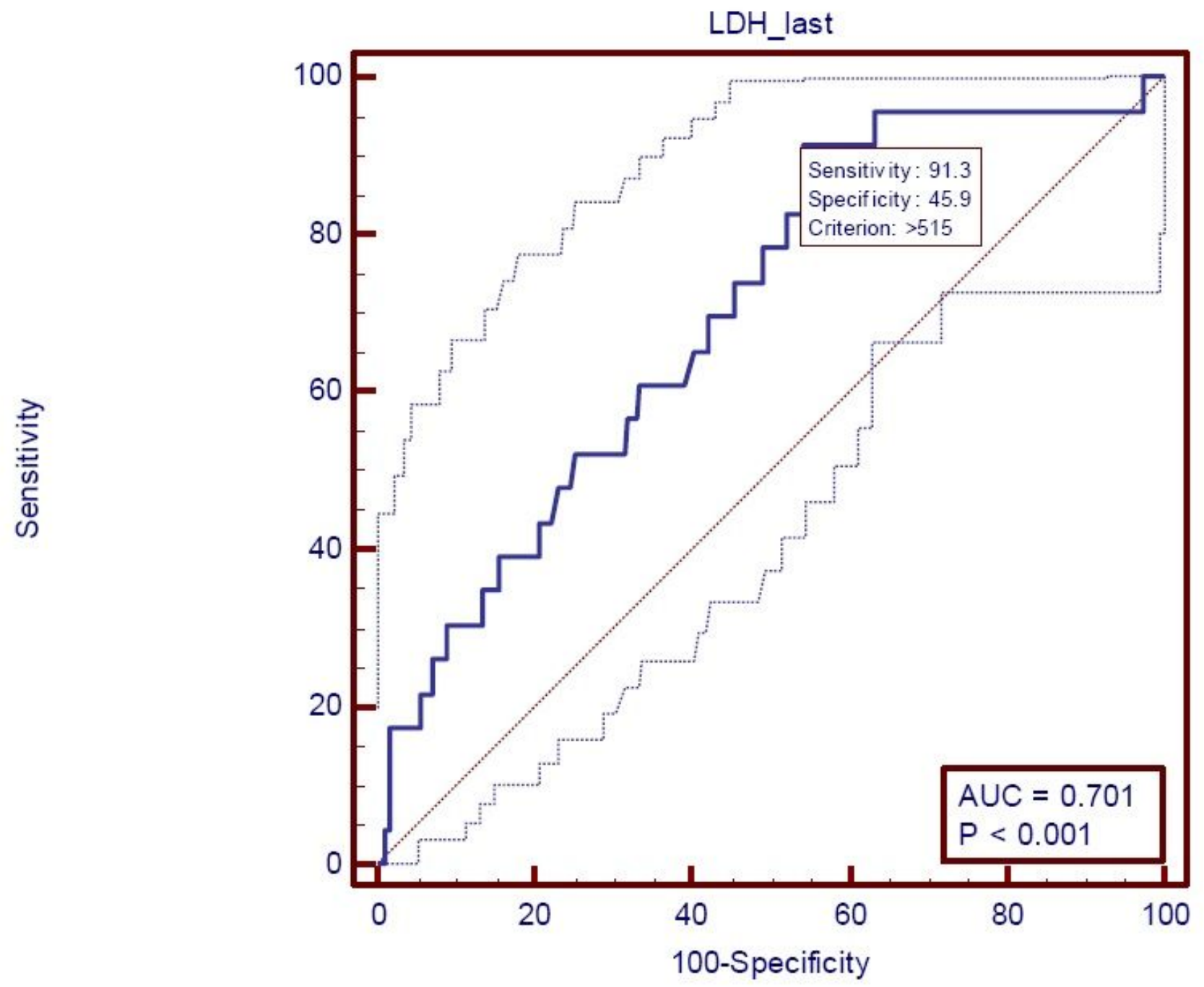

Area under the ROC curve (AUC)

\begin{tabular}{|l|r|}
\hline Area under the ROC curve (AUC) & 0.701 \\
\hline Standard Error ${ }^{\mathrm{a}}$ & 0.0556 \\
\hline $95 \%$ Confidence interval b & 0.636 to 0.761 \\
\hline z statistic & 3.625 \\
\hline Significance level P (Area=0.5) & 0.0003 \\
\hline
\end{tabular}

Figure 1

An ROC curve (receiver operating characteristic curve) shows the best cut off point for LDH to predict hospital death. a DeLong et al., 1988 b Binomial exact 


\section{Supplementary Files}

This is a list of supplementary files associated with this preprint. Click to download.

- Idhchecklist.doc 